\title{
ESCRAVIDÃO DE AFRICANOS E FABRICAÇÃO DE MADEIRAS NO GRÃO-PARÁ NA SEGUNDA METADE DO SÉCULO XVIII
}

\author{
Regina Celia Correa Batista
}

Resumo: O que pretendo salientar nesse texto é a presença de africanos escravizados na fabricação de madeiras, na Capitania do Grão-Pará, principalmente em finais do século XVIII, quando já se sentia os efeitos da intensificação do tráfico de cativos africanos para a região, através da atuação da Companhia Geral de Comércio do Grão-Pará e Maranhão. Com base na documentação do Arquivo Histórico Ultramarino e Arquivo Público do Pará, se dialoga com a historiografia pertinente ao tema, principalmente aquela que busca problematizar o "vazio humano", que por vezes se pretendeu demonstrar em narrativas sobre a Amazônia colonial, escamoteado na visão de: região extrativista com utilização de mão-de-obra indígena (Vergolino-Henry \& Figueredo, 1990; Funes, 1995; Gomes, 1997; Bezerra Neto, 2012; Chambouleyron, 2004 e 2006; Barbosa, 2009; Silva, 2013).

Palavras-chave: escravidão, africanos, fabricação de madeiras, Grão-Pará.

\section{SLAVERY OF AFRICANS AND WOOD MAKING IN GRÃO-PARÁ IN THE SECOND HALF OF THE 18TH CENTURY}

\begin{abstract}
What I intend to emphasize in this text is the presence of enslaved Africans in the manufacture of wood, in the Captaincy of Grão-Pará, mainly at the end of the 18th century, when the effects of the intensification of trafficking in African captives to the region were already felt, through the activities of the General Trading Company of GrãoPará and Maranhão. Based on the documentation of the Overseas Historical Archive and the Public Archive of Pará, a dialogue with the historiography pertinent to the theme, especially that which seeks to problematize the "human void", which was sometimes intended to be demonstrated in narratives about the colonial Amazon, concealed in the view from: extractive region with the use of indigenous labor (Vergolino-Henry \&

\footnotetext{
1 Doutoranda no Programa de Pós-Graduação em História Social da Amazônia da Universidade Federal do Pará (PPHIST/UFPA). Atua na área de Educação e História Social da Amazônia, principalmente História da Amazônia Colonial. Professora efetiva da Secretaria Municipal de Educação de Marabá/PA. Integrante do Laboratório e Grupo de pesquisa Interpretação do Tempo: ensino, memória, narrativa e política (ITEMNPO). CNPq/UNIFESSPA. Integrante do Grupo de Estudos e Pesquisas Amazônia Colonial (PPHIST/UFPA). E-mail regihistoria@yahoo.com.br
} 
Figueredo, 1990; Funes, 1995; Gomes, 1997; Bezerra Neto, 2012; Chambouleyron, 2004 and 2006; Barbosa, 2009; Silva, 2013).

Keywords: slavery, Africans, wood making, Grão-Pará.

\section{LA ESCLAVITUD DE LOS AFRICANOS Y LA FABRICACIÓN DE MADERA EN GRÃO-PARÁ EN LA SEGUNDA MITAD DEL SIGLO XVIII}

Resumen: Lo que pretendo enfatizar en este texto es la presencia de africanos esclavizados en la fabricación de madera, en la Capitanía de Grão-Pará, principalmente a fines del siglo XVIII, cuando los efectos de la intensificación del tráfico de cautivos africanos a la región ya se sentían, a través de las actividades de la Compañía Comercial General de Grão-Pará y Maranhão. Basado en la documentación del Archivo Histórico de Ultramar y el Archivo Público de Pará, un diálogo con la historiografía pertinente al tema, especialmente el que busca problematizar el "vacío humano", que a veces se pretendía demostrar en narrativas sobre la Amazonía colonial, oculto en la vista de: región extractiva con uso de mano de obra indígena (Vergolino-Henry \& Figueredo, 1990; Funes, 1995; Gomes, 1997; Bezerra Neto, 2012; Chambouleyron, 2004 y 2006; Barbosa, 2009; Silva, 2013).

Palabras clave: esclavitud, africanos, fabricación de madera, Grão-Pará.

\section{ESCLAVAGE DES AFRICAINS ET FABRICATION DU BOIS A GRÃO-PARA DANS LA SECONDE MOITIE DU XVIIIE SIECLE}

Résumé: Ce que j'ai l'intention de souligner dans ce texte, c'est la présence d'esclaves africains dans la fabrication du bois, dans la capitainerie de Grão-Pará, principalement à la fin du XVIIIe siècle, lorsque les effets de l'intensification du trafic de captifs africains dans la région se faisaient déjà sentir, à travers les activités de la General Trading Company de Grão-Pará et Maranhão. Sur la base de la documentation des archives historiques d'outre-mer et des archives publiques du Pará, un dialogue avec l'historiographie pertinente au thème, en particulier celui qui cherche à problématiser le «vide humain», qui était parfois destiné à être démontré dans des récits sur l'Amazonie coloniale, caché dans la vue de: région d'extraction avec recours à la main-d'œuvre indigène (Vergolino-Henry et Figueredo, 1990; Funes, 1995; Gomes, 1997; Bezerra Neto, 2012; Chambouleyron, 2004 et 2006; Barbosa, 2009; Silva, 2013).

Mots-clés: esclavage, Africains, fabrication du bois, Grão-Pará.

\section{INTRODUÇÃO}

Profícua produção historiográfica já demonstrou que os nativos tenderam a ser sujeitos essenciais para a colonização europeia que se desenrolou na região amazônica

Revista da ABPN • v. 12, n. Ed. Especial - Caderno Temático: "Africanos, escravizados, libertos biografias, imagens e experiências atlânticas” • agosto de 2020, p. $71-88$ 
entre os séculos XVI e XIX (Almeida, 1990; Farage, 1991; Cunha, 1992; Almeida, 1997; Coelho, 2005 e Souza Junior, 2009). No que se refere à engrenagem da fabricação de madeiras, essa constatação não foi diferente. A intensa e compulsória utilização de mãode-obra indígena, perpassando pelos meandros de suas estratégias de ação no processo, são elementos importantes para entendermos as vicissitudes dessa atividade (Batista, 2013). No entanto, apesar de central, os indígenas não foram os únicos sujeitos que desempenharam suas atividades na fabricação de madeiras na região.

Principalmente a partir de meados do século XVIII, se desenvolveu na Capitania do Grão-Pará uma intensa atividade de extração e fabricação de madeiras da região para atender as demandas de uso e comércio desse importante recurso. As Fábricas de Madeiras instaladas no vale do Tocantins eram unidades controladas pelo Estado, arrendando a administração através dos Contratos de Fabricação das Madeiras, geralmente arrematado por homens de negócios da região.

Tais unidades eram responsáveis por fabricar as madeiras necessárias para as Encomendas Reais, principalmente destinadas para os Arsenais Reais da Marinha e Exército, em Lisboa, mas também, para atender as demandas do Arsenal Real do Pará, o Arsenal de São Boaventura, instalado em Belém em 1761. Neste local se construíram várias embarcações ao longo do século XVIII e XIX. Com o aumento da procura por madeiras, essas Fábricas foram se espalhando pela região, lançando mão das árvores da região e utilizando-se dos rios para escoar a produção e da mão-de-obra dos nativos e dos cativos de origem africana.

O intuito deste texto é salientar a participação efetiva de pessoas escravizadas de origem africana nesta atividade e contribuir com a discussão acerca da importante participação desses sujeitos no processo de colonização que se desenrolou na região a partir do século XVII, problematizando a visão de exclusividade de mão-de-obra indígena e participação incipiente de cativos de origem africana nas Capitanias do Norte, durante muito tempo apregoada por parte da historiografia que versou acerca dessa temática.

\section{GENTE AFRICANA ESCRAVIZADA NO PARÁ}

Revista da ABPN • v. 12, n. Ed. Especial - Caderno Temático: "Africanos, escravizados, libertos biografias, imagens e experiências atlânticas” • agosto de 2020 , p. $71-88$ 
Várias foram as tentativas do governo português em estimular o tráfico de pessoas escravizadas de origem africana para a região, mesmo antes da vigência do monopólio da Companhia de Comércio. Por exemplo, as Provisões Régias de 18 de março de 1662 e 01 de abril de 1680. A primeira, estabelecia o livramento da metade dos direitos os negros de Angola que fossem introduzidos no Maranhão. A segunda, determinava o envio anual de negros da Guiné para o Maranhão e Pará por conta da Fazenda Real. Em 1682 foi fundada a Companhia de Comércio do Maranhão, com intento de atuar principalmente na exportação de açúcar e algodão, fornecimento de crédito, transporte e cativos africanos aos produtores. Tais iniciativas foram responsáveis pela trazida de pelo menos mil cativos africanos para a região, entre o final do século XVII e primeira metade do século XVIII. (Silva, 2012 e Barbosa, 2009) Cifras que, se colocadas em relação à população geral, não são desprezíveis e expressam a participação de uma população de origem africana na Amazônia colonial, em período no qual se costumava negar a presença desses sujeitos na região. (Chambouleyron, 2006)

Sobre as possíveis causas de intensificação dessa diáspora compulsória de pessoas africanas escravizadas, a historiografia já demonstrou alguns fatores gestados dentro do próprio processo de colonização europeia vigente na região, dentre os principais: a querela entre religiosos e colonos pela mão-de-obra indígena; as seguidas epidemias que afetavam principalmente a população indígena, qual não tinha resistência às doenças trazidas pelo colonizador e o horizonte do modelo de colonização monocultora para exportação à base de mão-de-obra escravizada africana praticada no estado do Brasil.

Para os moradores, a introdução de mão-de-obra escrava africana representava uma alternativa para resolver as dificuldades enfrentadas com a aquisição de trabalhadores nativos. Eles acusavam os religiosos, principalmente os da Companhia de Jesus, de monopolizarem os indígenas pra seus serviços e dificultarem o acesso dos moradores à esta mão-de-obra. Os religiosos, por sua vez, denunciavam os constantes abusos sofridos pelos indígenas, quando em poder dos moradores. Além disso, contribuiria para resolver a questão da legitimidade da escravização indígena, questionada pelos religiosos. Para os religiosos da Companhia de Jesus, o êxito da sua 
proposta "salvacionista" dependia fundamentalmente da tutela que os mesmos possuíam sob os nativos, por meio da qual tinham a possibilidade de atuar através da catequese. ${ }^{2}$

Essa querela entre moradores e religiosos era agravada pelos vários surtos epidêmicos que assolavam populações. As epidemias foram responsáveis por momentos de altos índices de mortalidade, principalmente entre os nativos. Segundo estudos de Chambouleyron et al. (2011) de meados do século XVII à meados do século XVIII, há registros de epidemias nas décadas de 1660, 1690, 1720 e 1740. Os autores concluíram que os vários surtos de doenças ensejaram relevantes transformações nas formas de aquisição e uso de força de trabalho da região, atuando na intensificação de descimentos privados e organização da rota do tráfico negreiro. Principalmente nesses períodos, moradores e autoridades costumavam intensificar seus pedidos por cativos africanos, para suprir a necessidade de mão-de-obra. (Barbosa, 2009)

Em 1726, o senhor de engenho Jerônimo Vaz Vieira solicita que lhe fossem vendidos vinte cativos africanos daqueles que chegavam na capitania do Pará, devido terem morrido "mais de cincoenta escravos operários (...) por causa da epidemia que he notório houve naquellle estado". 3 Os sucessivos surtos epidêmicos provocavam um grande tensionamento nas já recorrentes querelas por mão-de-obra. Em meados do século XVIII, uma carta dos Oficiais da Câmara de Belém, representando os homens de negócios do estado, expõe suas queixas após as consequências deixadas por um surto epidêmico ocorridos na década de 1740. Os oficiais explicitavam na carta:

O lamentável estado em que se achava esta cidade e suas anexas, por cauza de hua rigorosa epidemia, que a todos tem cauzado e reduzido a mizeria e penúria de seos princípios, sendo mais considerável estrago na escravatura, dos quais, estão os moradores tão destetuhidos que se vem as suas lavouras e cultura sem beneficio algum, no que tão bem tem grande falta e prejuízo a Real Fazenda de S. Mage. ${ }^{4}$

\footnotetext{
${ }^{2}$ Para aprofundar a discussão acerca da ideologia jesuítica sobre a escravidão indígena e africana ver: SOUZA-JÚNIOR. José Alves. Tramas do cotidiano: religião, política, guerra e negócios no Grão-Pará do setecentos. Belém. Ed. da UFPA. 2012. Originalmente apresentada como Tese de Doutorado - PUC. São Paulo. 2009.

${ }^{3}$ REQUERIMENTO de Jerónimo Vaz Vieira, para o rei [D. João V], datada de 12 de junho de 1726. Projeto Resgate/Arquivo Histórico Ultramarino/Pará_ACL_CU_013, Cx. 9, D. 824.

${ }^{4}$ CARTA ( $2^{\mathrm{a}}$ Via) dos Oficiais da Câmara da cidade de Belém do Pará, para o rei (D. José I), datada de 15 de setembro de 1750. Projeto Resgate/Arquivo Histórico Ultramarino/Pará_ACL_CU_013, Cx. 32, D. 3001 .
} 
É notório no argumento dos oficiais a ênfase na "extrema necessidade" que os produtores estavam enfrentando. Também fica evidente o tom de "justificativa" para que a Coroa concorresse com ajuda para os mesmos, haja vista que, sem produção, a arrecadação dos dízimos ficaria prejudicada. Para acudir aos moradores, os oficiais solicitam que lhes seja permitido a execução de algumas tropas de resgate, pois já haviam tido o pedido dessa diligência negado pelo governador, com "o pretexto de que V. Mage. tinha mandado impedir as referidas tropas". 5

Também pontuam os oficiais sobre os tensionamentos com os religiosos acerca da distribuição de mão-de-obra nativa, sugerindo que, caso não consigam ser atendidos em seu requerimento, a consequência poderia ser que:

Este povo em hua grande consternação, q' poderá desertar, já como de esperado e com muita mayor razão, vendo estes que só os religiosos tem escravos, allem das aldeyas que lhe estão subordinadas para as repartirem com os moradores, segundo as ordens de V. Mage. e eles o fazem tanto pello contrario q' só repartem por sy os ditos índios, pois não se despede canoa de cada missionário que não leve secenta, setenta, oitenta negros $\mathrm{p}^{\mathrm{a}}$ as faturas de cacao, cravo, salsa, cravo fino, tartaruga, manteiga e peixe seco. ${ }^{6}$

E finalmente pontuam ainda os oficiais que "como este remédio não seja ainda bastante, para reforma de tantos milhares de escravos que pereserão nesta tão abominável peste, rogamos a V. mage. se digne mandar algum navio de pretos $\mathrm{p}^{\mathrm{a}}$ se repartirem com os moradores". ${ }^{7}$ A despeito de um certo exagero no argumento dos oficiais, construído debaixo das expectativas em ter seu pedido de ajuda atendido pela Coroa, fica evidente que as experiências com os surtos epidêmicos e as querelas com os religiosos, foram

\footnotetext{
${ }^{5}$ Idem. Sobre o sistema de recrutamento de trabalhadores indígenas na região amazônica até meados do século XVIII, ver: CHAMBOULEYRON. Rafael \& BOMBARDI. Fernanda Aires. Descimentos privados de índios na Amazônia colonial (séculos XVII e XVIII). Varia História, vol. 27, n. 46, Belo Horizonte, 2011, p. 601-623; DIAS. Camila Loureiro \& BOMBARDI. Fernanda Aires. O que dizem as licenças? Flexibilização da legislação e recrutamento particular de trabalhadores indígenas no Estado do Maranhão (1680-1755). Revista de História (São Paulo), nº 175, jul/dez 2016, p. 249-280.

${ }^{6}$ CARTA ( $2^{\text {a }}$ Via) dos Oficiais da Câmara da cidade de Belém do Pará, para o rei (D. José I), datada de 15 de setembro de 1750. Projeto Resgate/Arquivo Histórico Ultramarino/ Pará_ACL_CU_013, Cx. 32, D. 3001.

${ }^{7}$ Idem.
}

Revista da ABPN • v. 12, n. Ed. Especial - Caderno Temático: "Africanos, escravizados, libertos biografias, imagens e experiências atlânticas” • agosto de 2020, p. $71-88$ 
dando a tonalidade das propostas de atuação do estado na região. Esse é um olhar importante para entendermos as chamadas políticas pombalinas na Amazônia. ${ }^{8}$

Esse tensionamento qual já vinha sendo gestado principalmente desde a primeira metade do século XVIII, como demonstrado nos parágrafos anteriores, ganha mais visibilidade com a emergência do governo de D. José I e seu Ministro de Negócios do Reino, Sebastião José de Carvalho e Melo (o Marquês de Pombal). Para governar o Estado, Sebastião José enviou seu irmão, Francisco Xavier de Mendonça Furtado. As experiências do governador compartilhadas com seu irmão no reino, foram conformando a atuação da nova administração no estado. Desse processo culminaram, entre outras medidas, a expulsão dos jesuítas da Amazônia e posteriormente, de todas as possessões lusas; a Lei da Liberdade dos Índios e a Criação de uma Companhia de Comércio.

Em carta de 1751, Francisco Xavier de Mendonça Furtado explicita ao reino a dificuldade em atender a incumbência que lhe foi atribuída de pôr em prática a liberdade dos índios. Segundo ele,

Todos esses homens, se de repente se vissem sem os que eles chamam escravos; as poucas lavouras que há paradas; os outros que não sabem pescar, nem caçar, mortos de fome, sem remédio humano; os índios, em virtude da sua liberdade, espalhados por estes sertões, ou talvez em mocambos para o que todos têm propensão, e tudo isto de repente; eu, sem meios de poder juntar os tais índios para os dar por criados àqueles de quem tinham sido escravos, é certo que poderiam progredir aqueles trabalhosos efeitos em que costumam romper muitas vezes as desesperações, e a Praça totalmente sem forças para poder conter aos moradores de passarem a alguma desordem. ${ }^{9}$

Para Mendonça Furtado, a maneira de se evitar o colapso era a reestruturação das atividades de acordo com novos dimensionamentos e sugeria que a melhor maneira de convencer os colonos locais a desistirem da escravização dos nativos era compensá-los com a introdução sistemática de cativos africanos no estado, por preços subsidiados.

\footnotetext{
${ }^{8}$ Importante estudo, nesse sentido, é a tese do historiador Mauro Coelho, na qual conclui que a Lei do Diretório dos Índios foi construída pelas demandas da Colônia. Ver: COELHO, Mauro Cesar. "Do Sertão Para o Mar - Um estudo sobre a experiência portuguesa na América, a partir da colônia: o caso do Diretório dos Índios (1751-1798)”. São Paulo. Universidade de São Paulo, 2005. (Tese de doutorado)

${ }^{9}$ CARTA de Francisco Xavier de Mendonça Furtado para Diogo de Mendonça Corte Real. Datada de 30 de novembro de 1751. MENDONÇA. Marcos Carneiro de. A Amazônia na Era Pombalina: correspondência do governador do estado do Grão-Pará e Maranhão, Francisco Xavier de Mendonça Furtado (1751-1759). Tomo II. 2a edição: Brasília. Senado Federal, 2005, p. 133.
}

Revista da ABPN • v. 12, n. Ed. Especial - Caderno Temático: "Africanos, escravizados, libertos biografias, imagens e experiências atlânticas” • agosto de 2020, p. $71-88$ 
(Sousa Júnior, 2012, p. 99) A construção dialética entre os interesses reinóis e dos negociantes locais levou a inauguração de uma Companhia de Comércio, através da qual fosse possível acudir ao estado caótico da economia do Grão-Pará e Maranhão, derivado da falta de braços, e assegurar o abastecimento em mercadorias essenciais, por meio de carreiras regulares de navios com Portugal. (Carreira, 1969, p. 31)

No ano de 1752, o governador Mendonça Furtado recebe uma carta régia sobre o propósito dos moradores do Maranhão de formarem uma companhia de comércio para introduzirem cativos africanos na região, ordenando que "dês licença, não só aos interessados na dita companhia, mas também a quaisquer dos homens de negócio dessa Capitania, que dela queiserem mandar embarcações a resgatar os ditos escravos na costa de Guiné, que introduzam nesse Estado". ${ }^{10}$

Os interesses locais, mediados pelas estratégias de convencimento do governador culminaram na inauguração da dita Companhia, em 1755. Em detrimento de apologistas ou detratores da Companhia, é notório que foi a partir da atuação da empresa monopolista que o número de pessoas escravizadas de origem africana se intensificou na região. Dados sistematizados nos dois estudos clássicos da Companhia de Comércio - Fomento e Mercantilismo: a Companhia Geral do Grão-Pará e Maranhão (1755-1778), de Manuel Nunes Dias e As Companhias pombalinas de navegação, comércio e tráfico de escravos entre a costa africana e o nordeste brasileiro, de Antônio Carreira - registram respectivamente 25.365 e 24.649 cativos africanos entrados no Estado no período de vigência do monopólio da Companhia. Exclusivamente no porto da Capitania do Pará, Dias indica a cifra de 14.749, enquanto que Carreira registra 13.834. Posteriormente, o historiador José Maia Bezerra Neto, indica a cifra de 17.627 cativos africanos ingressados no Grão-Pará no período de vigência do monopólio da companhia de comércio.

O percurso traçado até aqui nos mostra um cenário que nos permite afirmar da participação dos sujeitos de origem africana na construção do processo de colonização que se desenrolou no Pará. Como salientei no início deste texto, vários autores já haviam desconfiado deste "vazio humano". Segundo Vicente Salles, os cativos formavam a

\footnotetext{
${ }^{10}$ MENDONÇA. Marcos Carneiro de. A Amazônia na Era Pombalina: correspondência do governador do estado do Grão-Pará e Maranhão, Francisco Xavier de Mendonça Furtado (1751-1759). Tomo I. $2^{\mathrm{a}}$ edição: Brasília. Senado Federal, 2005, p. 389.
}

Revista da ABPN • v. 12, n. Ed. Especial - Caderno Temático: "Africanos, escravizados, libertos biografias, imagens e experiências atlânticas” • agosto de 2020 , p. $71-88$ 
criadagem das famílias ricas e executavam tarefas em todas as repartições das casas, desde a sala até a cozinha. (Salles, 2005, p. 212) Eles estavam em todos os setores da sociedade, muitos foram enviados para o trabalho no campo, outros inseridos nos diversos ramos das atividades urbanas, atuando em trabalho de particulares e também em obras públicas. A experiência desses sujeitos com as atividades relativas à fabricação de madeiras é o que pretendo traçar nas páginas seguintes.

\section{CATIVOS AFRICANOS NA FABRICAÇÃO DE MADEIRAS NO GRÃO-PARÁ}

As madeiras foram alvo de interesse do colonizador europeu desde o início. No estado do Maranhão têm-se registros de cargas de madeiras partindo para Lisboa desde o século XVII. ${ }^{11}$ Na década de 1730 foi instalada no Pará, mais precisamente às margens do rio Moju, uma estrutura para a fabricação das Madeiras Reais, ou seja, aquelas encomendadas pela Coroa principalmente para serem utilizadas na construção naval no Reino. ${ }^{12}$ Na Ribeira de Moju também se desenvolvia a fabricação de canoas, registros da época informam que algumas das canoas que foram enviadas para a expedição da qual participou Alexandre Rodrigues Ferreira foram construídas naquele local.

Fatores externos e internos a partir de meados do século XVIII provocaram uma nova leva de pressão para o aumento da fabricação de madeiras no estado. Por exemplo, a necessidade de restruturação da frota da marinha portuguesa, a restruturação de Lisboa após terremoto que arrasou a cidade em 1755, os novos cânones da política administrativa

\footnotetext{
${ }^{11}$ Ver: OFÍCIO de Roque da Silveira, sobre os navios que vão para o Maranhão e que no regresso transportariam madeiras. Datado de 16 de abril de 1622. Resgate/Arquivo Histórico Ultramarino/ Maranhão_ACL_CU_009, Cx. 1, D. 38.

${ }^{12}$ Ver: CARTA do provedor da Fazenda Real [da capitania do Pará], Matias da Costa e Sousa, para o rei [D. João V], datada de 07 de setembro de 1733. Projeto Resgate/ Arquivo Histórico Ultramarino/ Pará_ACL_CU_013, Cx. 15, D. 1405; CARTA do provedor-geral da Fazenda Real da capitania do Pará, Matias da Costa e Sousa, para o rei [D. João V], datada de 13 de agosto de 1737. Projeto Resgate/Arquivo Histórico Ultramarino/ Pará_ACL_CU_013, Cx. 20, D. 1862; OFÍCIO do [secretário do Governo do Estado do Maranhão], António da Rocha Machado para o [secretário de estado da Marinha e Ultramar, António Guedes Pereira], datado de 07 de outubro de 1737. Projeto Resgate/Arquivo Histórico Ultramarino/Pará_ACL_CU_013, Cx. 20, D. 1876; OFÍCIO do [governador e capitão-general do Estado do Maranhão e Pará], João de Abreu de Castelo Branco, para o [secretário de estado da Marinha e Ultramar], António Guedes Pereira, datada de 11 de outubro de 1741. Projeto Resgate/Arquivo Histórico Ultramarino/ Pará_ACL_CU_013, Cx. 24, D. 2263.
} 
de D. José I e seu Ministro, o Marquês de Pombal, o interesse de alguns homens de negócio da Capitania em expandirem seus negócios e ganharem prestígio no Estado.

Na década de 1760 é instalado o Arsenal Real do Pará, o Arsenal de São Boa Ventura, às margens do rio Pará, para construção de embarcações maiores no estado. Dessa feita, se fez necessário aumentar as encomendas de madeiras, que além de servirem para serem enviadas para os arsenais do reino, também deveria abastecer o arsenal do estado. Em carta de 1761 o governador informa a Corte o seguinte:

No que respeita ao empreiteiro das madeiras, devo dizer a V. Ex ${ }^{\mathrm{a}}$, que temendo o não ser S. Mage. bem servido, sendo elle obrigado ao corte das madeiras para a carga das duas charruas, e juntamente para a construção da não, porq' é impossível a sua vigilância em tão distantes lugares como sam precisos aos diferentes cortes, mandei chamar o carpinteiro Pedro de Alcântara, porq' por ser o mais capaz, se obrigue ao sobredito corte das madeiras $\mathrm{p}^{\mathrm{a}}$ a fábrica da nova nao. $^{13}$

Com a necessidade de atender também a construção naval do estado, houve a necessidade de se ampliar os cortes e com isso, mais demanda de trabalhadores. $\mathrm{Na}$ correspondência supracitada, o governador informa já ter tomado algumas providências para adiantar a obra de construção do estaleiro "enquanto S. Mage. não dá a providência e resolve sobre a proposta [...] a respeito da introdução dos pretos $\mathrm{p}^{\mathrm{a}} \mathrm{o}$ serviço da fábrica, por conta da Fazenda Real". ${ }^{14}$

Tendo sempre no horizonte a questão da mão-de-obra, o novo contrato para fabricação das madeiras reais foi arrematado por João Gonçalves Calheiros em 1774 para vigência de três anos. O mesmo era um típico sujeito da "elite paraense"15 daquele período. Morador da cidade de Belém, era um sujeito envolvido na economia e política do estado. Registrado no mapa das famílias de 1778 como morador da freguesia da Sé na

\footnotetext{
${ }^{13}$ OFÍCIO do governador e capitão-general do Estado do Grão-Pará e Maranhão, Manuel Bernardo de Melo e Castro, para o [secretário de estado da Marinha e Ultramar], Francisco Xavier de Mendonça Furtado, datado de 21 de julho de 1761. Projeto Resgate/Arquivo Histórico Ultramarino/Avulsos Pará_ACL_CU_013, Cx. 50, D. 4589.

${ }^{14}$ Idem.

${ }^{15}$ Sobre isso ver: SOUZA JUNIOR. op, cit. CARDOSO, Alana Souto, "Apontamentos para História da Família e Demografia Histórica da Capitania do Grão-Pará (1750-1790)”. Dissertação de mestrado em História Social da Amazônia. UFPA. 2008.
}

Revista da ABPN • v. 12, n. Ed. Especial - Caderno Temático: "Africanos, escravizados, libertos biografias, imagens e experiências atlânticas” • agosto de 2020, p. $71-88$ 
cidade, ocupava o posto de capitão auxiliar, lavrador, casado, 4 pessoas na sua família, um plantel de 70 pessoas escravizadas. ${ }^{16}$

No contrato entregue à João Gonçalves Calheiros fica evidente o impacto que as políticas de inserção de cativos africanos no estado tiveram nesse tipo de atividade. Em contratos anteriores, eram disponibilizados cento e sessenta índios para o trabalho na fábrica, ficando os empreiteiros responsáveis por seus pagamentos. No atual contrato, fica reduzido ao número de vinte o emprego desses trabalhadores, sendo o restante de trabalhadores necessários complementados pelos escravos do atual empreiteiro. ${ }^{17}$

Frente às querelas enfrentadas pela administração lusa acerca da arregimentação compulsória de trabalhadores nativos, a entrega do contrato de fabricação das madeiras para alguém que possuísse sua própria mão-de-obra parecia uma boa opção para levar adiante essa atividade no estado. Uma carta do governador Pereira Caldas ao Reino nos permite flagrar a provável participação do plantel de pessoas escravizadas de João Gonçalves Calheiros na fabricação de madeiras. Segundo o governador, um dos motivos para que algumas madeiras das encomendas reais fossem enviadas com dimensões superiores às solicitadas era devido as mesmas serem "feitas devidida e separadamente pellos centros do matto, e que sendo ali mesmo, lavrados os paos por índios e pretos, que nem sempre podem ter junto de cada pao hum official, que lhe determine as justas, e determinadas dimensões". ${ }^{18}$

Seu sucessor no contrato, Pedro de Azevedo Bagunte, também era um sujeito envolvido diretamente com a fabricação de canoas. Morador da freguesia da Sé, na cidade, o mesmo era empreiteiro do estaleiro da Companhia de Comércio, empresa envolvida com o tráfico de pessoas escravizadas na região, ou seja, Pedro Bagunte estava

\footnotetext{
${ }^{16}$ OFÍCIO do [governador e capitão general da capitania do Rio Negro], João Pereira Caldas, para o [secretário de estado da Marinha e Ultramar], Martinho de Melo e Castro, datado de 22 de junho de 1785. Projeto Resgate/Arquivo Histórico Ultramarino/Pará_ACL_CU_013, Cx. 94, D. 7509.

${ }^{17}$ OFÍCIO do governador e capitão general do Estado do Pará e Rio Negro, João Pereira Caldas, para o [secretário de estado da Marinha e Ultramar], Martinho de Melo e Castro, datado de 08 de julho de 1774. Projeto Resgate/Arquivo Histórico Ultramarino/Pará_ACL_CU_013, Cx. 73, D. 6148.

${ }^{18}$ OFÍCIO do [governador e capitão-general do Estado do Pará e Rio Negro], João Pereira Caldas, para o [secretário de estado da Marinha e Ultramar], Martinho de Melo e Castro, datado de 08 de agosto de 1776. Projeto Resgate/Arquivo Histórico Ultramarino/Pará_ACL_CU_013, Cx. 75, D. 6334.
}

Revista da ABPN • v. 12, n. Ed. Especial - Caderno Temático: "Africanos, escravizados, libertos biografias, imagens e experiências atlânticas” • agosto de 2020 , p. $71-88$ 
ligado tanto ao tráfico de cativos africanos quanto à fabricação de embarcações, atributos que podem ter influenciado na sua indicação para assumir o contrato das madeiras.

Parece que a antiga problemática com a mão-de-obra para levar adiante a atividade estava sempre voltando ao centro das preocupações. Em 1789, queixava-se o governador sobre a dificuldade em manter pessoas interessadas em continuar fabricando madeiras no estado. Segundo ele, em relação aos cativos de origem africana os problemas residiam na diminuição do tráfico para a região naquele período, os altos preços e o pouco prazo para pagamento. Sobre essas questões, o governador dizia o seguinte:

No tempo da extinta Companhia, não só fazia esta huma sufficiente introdução delles, mas vendendo-os fiado e pode-se dizer, a arbitrio dos governadores assim pelo q' respeita ao preço, que de ordinário era cento e quinze mil reis, os de primeiro lote, como a sua destribuição, podião as ditas fábricas neste cazo serem auxuliadas com hum sufficiente numero de operarios. Hoje que a introdução dos mesmos escravos é menor e o seu preço tem chegado a cento e sessenta mil reis, dinheiro à vista ou com huma muito limitada espera $\mathrm{p}^{\mathrm{a}} \mathrm{o}$ seu pagamento, como hé possível $\mathrm{Exm}^{\circ} \mathrm{Sr}$ que esses homens desempenhem bem as suas funções, e como poderei eu levá-los para satisfazer as minhas? ${ }^{19}$

Estudos mais recentes demonstram que o período posterior a atuação da companhia não representou uma menor introdução de cativos na região, como quis argumentar o governador. Ao contrário, José Maia Bezerra Neto registra a cifra de 17.970 cativos africanos trazidos ao Pará no período de 1778 à 1800 (Bezerra Neto, 2012, p. 202). Todavia, se houve uma intencional ou não argumentação do governador sobre a diminuição do quantitativo de cativos naquele período, se verifica registros de tumultos provocados pelos moradores no momento da venda desses cativos, já no período de atuação da companhia de comércio, indicando que havia disputa pela compra dos lotes, insuficientes para a demanda dos moradores (Alves Júnior. 2012, pp. 167-168).

A tópica da "falta de braços" defendida tanto pelos moradores, quanto por administradores foi uma recorrente nos documentos daquele período (Chambouleyron, 2004; Silva, 2012). O Estado procurava manter o monopólio do poder sobre a

${ }^{19}$ OFÍCIO do [governador e capitão general do Estado do Pará e Rio Negro], Martinho de Sousa e Albuquerque, para o [secretário de estado da Marinha e Ultramar], Martinho de Melo e Castro. Datado de 06 de agosto de 1789. Projeto Resgate/Arquivo Histórico Ultramarino/Pará_ACL_CU_013, Cx. 98, D. 7839 . 
administração da mão-de-obra, neste sentido, Martinho de Sousa e Albuquerque expõe as providências por ele tomadas para auxiliar as fábricas. Segundo ele, o empreiteiro de uma das fábricas, Joaquim Vicente Foro, possuía “préstimo e actividade para continuar no corte das madeiras, via com effeito que elle não tinha os precisos operários para ella [...]. Consegui que a elle se associasse o ajudante de auxiliares, João de Amaral Coutinho por ter huma porção de escravos costeados já em similhantes serviços. ${ }^{20}$

Pelo exposto, João de Amaral Coutinho era um sujeito já envolvido com a fabricação de madeiras, utilizando para isso seu plantel de escravos. Provavelmente era um dos fabricantes particulares, que muitas vezes também eram acionados pelo estado pra venderem suas peças para completar as encomendas reais. Com a justificativa de que as fábricas reais não estavam conseguindo suprir as necessidades das encomendas reais, a administração recorria aos fabricantes particulares. Sobre isso dizia o governador:

Essa falta de mêios e impossibilidades que ocorrem para não poderem os empreiteiros fazer maior e mais bem escolhida porção de madeiras tem obrigado também a lançar mão de algumas que várias vezes se tem oferecido pellos donos das próprias mattas aonde se encontrarão e elles apromptarão, aos quaes se comprão pelo estabelecido prêço, como se paga ao empreiteiro, sem outra attenção mais que a qualidade e prestimos das mesmas madeiras, e oxalá, que houvessem mais vendedores deste gênero. ${ }^{21}$

Além das encomendas da Coroa, os cativos africanos também estavam fabricando madeiras para particulares. Antônio Roiz Guedes e Ignácio Freire Fonseca, eram fabricantes de madeiras, moradores da freguesia de Santa Anna, na cidade de Belém. O primeiro, possuía vinte e cinco pessoas escravizadas e o segundo, vinte e quatro. ${ }^{22} \mathrm{Na}$ freguesia da Sé, também na cidade de Belém, Estevão da Silva Jaques, possuía vinte pessoas escravizadas e se dedicava a lavrar farinha, arroz e fabricar madeiras. ${ }^{23} \mathrm{O}$ já

\footnotetext{
${ }^{20}$ Idem.

${ }^{21}$ Idem.

22 OFÍCIO do [governador e capitão-general do Estado do Pará e Rio Negro], João Pereira Caldas, para o [secretário de estado da Marinha e Ultramar], Martinho de Melo e Castro, datado de 22 de junho de 1785. Projeto Resgate/Arquivo Histórico Ultramarino/Pará_ACL_CU_013, Cx. 94, D. 7509.

${ }^{23}$ Idem.
}

Revista da ABPN • v. 12, n. Ed. Especial - Caderno Temático: "Africanos, escravizados, libertos biografias, imagens e experiências atlânticas” • agosto de 2020, p. $71-88$ 
citado empreiteiro de uma das fábricas de madeira, Pedro de Azevedo Bagunte, também foi registrado nessa freguesia, rico, possuidor de um plantel de 32 pessoas escravizadas. ${ }^{24}$

A fabricação de madeiras, principalmente aquela das encomendas reais, exigia uma exaustiva jornada de trabalho, que envolvia adentrar as matas, escolher as melhores árvores para transformar em madeira, debastar os troncos e lavrar em peças específicas. Ainda puxar essas madeiras para a borda d'água para serem embarcadas nas canoas que as transportavam para a cidade de Belém, para dali serem utilizadas no Arsenal ou embarcadas para o Reino. Nessa jornada, muitos trabalhadores acabavam perdendo a vida. Exemplar nesse sentido temos o caso dos vinte e seis cativos da sociedade de Joaquim Vicente Foro, João de Amaral Coutinho e Manuel Duarte Gomes, que morreram durante o período no qual se dedicaram a fabricação de madeiras entre os anos de 1784 a 1789. Tendo em vista que iniciaram o contrato com cinquenta e seis cativos e não termos notícias de algum surto epidêmico de considerável alcance nesse período ${ }^{25}$, podemos inferir que quase metade desses trabalhadores perderam a vida em decorrência do desempenho de suas atividades no mundo do trabalho.

Importantes estudos acerca de doenças e mortalidade entre a população escravizada tem demonstrado que a causa das mortes eram o resultado de uma complexa correlação entre descaso, doenças, maus tratos, bem como condições inadequadas de moradia, alimentação e vestuário (Gorender, 1978; Schwartz, 1988; Karasch, 2000) Mais recentemente, Maíra Fernanda de Melo e Hilton Pereira da Silva realizam importante estudo relacionando a saúde em comunidades quilombolas com os Determinantes Sociais da Saúde (DSS). Os autores observaram que há um elevado índice de doenças crônicas que acometem essas populações negras rurais, em comparação com o restante da população brasileira. (Melo \& Silva, 2016) Tais estudos demonstram como a experiência da escravização de pessoas marcou a trajetória da população negra e indicam a persistência de práticas de iniquidade e distanciamento entre os grupos diversos de sujeitos que compõe a sociedade brasileira.

\footnotetext{
${ }^{24}$ Idem.

${ }^{25}$ Sobre os surtos epidêmicos na segunda metade do século XVIII no Pará ver: VIANNA. Arthur. As Epidemias no Pará. 2ed. Belém: UFPA, 1975; MARTINS. Roberta Sauaia. Do Sarampão as perniciozissimas bexigas: Epidemias no Grão-Pará setecentista (1748-1800). Dissertação de mestrado. PPHIST/UFPA. Belém, 2017.
} 


\section{CONSIDERAÇÕES FINAIS}

A segunda metade do século XVIII foi, como demonstrado, um período que catalisou mão-de-obra escravizada de origem africana para os trabalhos na fabricação de madeiras. Seja nas fábricas reais ou na produção de particulares, esses sujeitos imprimiram um novo cenário no que concerne às relações de trabalho nessas atividades, estando ao lado de nativos e demais operários de origem europeia, participando da engrenagem da produção. Essa presença tendeu a se potencializar ainda mais no avançar do século XIX, sendo ainda mais marcante em finais do período colonial e durante todo o período imperial (Palha, 2011).

Nota-se, pelo exposto, que a fabricação de madeiras no estado era, neste momento, bastante dependente da mão-de-obra cativa africana, apesar dos indígenas ainda continuarem como efetiva mão-de-obra entre os trabalhadores. A experiência desses sujeitos enquanto escravizados entranhou uma realidade que atravessou a história de formação da sociedade brasileira, provocando desigualdades. A dificuldade em flagrar os cativos neste tipo de trabalho perpassa, muitas das vezes, na limitação de fontes que registrem sua presença. Por exemplo, as relações de trabalhadores deste período que chegaram até nós através dos arquivos consultados, geralmente só registram aqueles trabalhadores livres. Como verificado neste texto, chegamos até nossos sujeitos cativos africanos através de informações de seus proprietários, esse ainda é um desafio a transpor. No entanto, ainda com os limites que esse tipo de abordagem possa apresentar, não podemos deixar de enfrentar essa questão e fazer o registro da presença importante desses sujeitos na fabricação de madeiras no estado e na formação da nossa sociedade.

\section{REFERÊNCIAS BIBLIOGRÁFICAS}

ALMEIDA, Maria Regina Celestino de. Trabalho compulsório na Amazônia: séculos XVIIXVIII. Revista Arrabaldes, ano I, nº 2 (set.-dez. 1988), p. 101-117.

Revista da ABPN • v. 12, n. Ed. Especial - Caderno Temático: "Africanos, escravizados, libertos biografias, imagens e experiências atlânticas” • agosto de 2020, p. $71-88$ 
ALMEIDA, Rita Heloísa de. O Diretório dos índios: um projeto de "civilização" dos índios no Brasil do século XVIII. Brasília: EdUnB: 1997.

ÂNGELO-MENEZES, Maria de Nazaré \& GUERRA, Gutemberg Armando Diniz. Exploração de Madeiras no Pará: semelhanças entre as fábricas reais do período colonial e as atuais serrarias. Cadernos de Ciência e Tecnologia, Brasília, volume 15, $\mathrm{n}^{\circ} 3$, (pp. 123-145, set/dez. 1998). Disponível em https://seer.sct.embrapa.br/index.php/cct/article/view/8948 acessado em: 12 jun. 2020.

BARBOSA, Benedito Carlos. Em outras margens do atlântico: tráfico negreiro para o Estado do Maranhão e Grão-Pará (1707-1750). Dissertação (Mestrado em História), Universidade Federal do Pará, Belém, PA, 2009.

BATISTA, Regina Célia Corrêa. Dinâmica populacional e atividade madeireira em uma vila da Amazônia: a vila de Moju (1730-1778). Dissertação (Mestrado em História), Universidade Federal do Pará, Belém, PA, 2013.

BEZERRA NETO, José Maia. Escravidão Negra no Pará (séculos XVII-XIX) 2 ed. Belém: Paka-Tatu: 2012.

CARREIRA, Antonio. As Companhias pombalinas de navegação, comércio e tráfico de escravos entre a costa africana e o nordeste brasileiro. Centro de Estudos da Guiné Portuguesa. Bissau, 1969.

CHAMBOULEYRON, Rafael \& BOMBARDI. Fernanda Aires. Descimentos privados de índios na Amazônia colonial (séculos XVII e XVIII). Varia História, vol. 27, n. 46, Belo Horizonte, 2011, p. 601-623. Disponível em https://www.scielo.br/pdf/vh/v27n46/11.pdf acessado em: 12 jun. 2020.

CHAMBOULEYRON, Rafael. Escravos do Atlântico equatorial: tráfico negreiro para o estado do Maranhão e Pará (séculos XVII e início do XVIII). Revista Brasileira de História, vol.26, ${ }^{\circ}$ 52(2006). Disponível em https://www.scielo.br/pdf/rbh/v26n52/a05v2652.pdf acessado em: 12 jun. 2020.

. Suspiros por um escravo de Angola. Discursos sobre a mão-de-obra africana na Amazônia seiscentista. Belém: Humânitas, vol.20, n 1/2 (2004), p. 141-63.

CHAMBOULEYRON, Rafael et al. Formidável contágio: epidemias, trabalho e recrutamento na Amazônia Colonial (1660 - 1750). História, Ciências, Saúde - Manguinhos, Rio de Janeiro, v. 18, n.4, out-dez. 2011, p. 987-1004. Disponível em https://www.scielo.br/pdf/hcsm/v18n4/02.pdf acessado em: 12 jun. 2020.

CARDOSO, Alana Souto. Apontamentos para História da Família e Demografia Histórica da Capitania do Grão-Pará (1750-1790). Dissertação (Mestrado em História), Universidade Federal do Pará, Belém, PA, 2008.

CUNHA, Manuela Carneiro da (org.). História dos índios no Brasil. São Paulo: Companhia das Letras, Secretaria Municipal de Cultura, FAPESP, 1992.

Revista da ABPN • v. 12, n. Ed. Especial - Caderno Temático: "Africanos, escravizados, libertos biografias, imagens e experiências atlânticas” • agosto de 2020 , p. $71-88$ 
DIAS, Camila Loureiro \& BOMBARDI, Fernanda Aires. O que dizem as licenças? Flexibilização da legislação e recrutamento particular de trabalhadores indígenas no Estado do Maranhão (16801755). Revista de História (São Paulo), $\mathrm{n}^{\circ}$ 175, jul/dez 2016, p. 249-280. Disponível em https://www.scielo.br/pdf/rh/n175/2316-9141-rh-175-00249.pdf acessado em: 10 jun. 2020.

DIAS, Manuel Nunes. Fomento e Mercantilismo: A Companhia Geral do Grão Pará e Maranhão (1775-1778). Belém, UFPA, 1970.

FARAGE, Nádia. As muralhas dos sertões: os povos indígenas no Rio Branco e a colonização. Rio de Janeiro: Paz e Terra, 1991.

FUNES, Eurípides. Nasci nas matas, nunca tive senhor. História e memória dos mocambos do Baixo Amazonas. Tese de Doutorado. São Paulo: USP, 1995.

GOMES, Flávio dos Santos. A Hidra e os Pântanos: quilombos e mocambos no Brasil (sécs. XVII-XIX). Campinas- SP, 1997.

GORENDER, Jacob. Escravismo Colonial. São Paulo: Ática, 1978.

KARASCH, Mary. A Vida dos Escravos no Rio de Janeiro (1808-1850). São Paulo: Cia. das Letras, 2000.

MARTINS. Roberta Sauaia. Do Sarampão as perniciozissimas bexigas: Epidemias no Grão-Pará setecentista (1748-1800). Dissertação (Mestrado em História), Universidade Federal do Pará, Belém, Pará, 2017.

MELO, Maíra Fernanda Tavares de; SILVA, Hilton Pereira. Doenças crônicas e os determinantes sociais da saúde em comunidades quilombolas do Pará, Amazônia, Brasil. Revista da Associação Brasileira de Pesquisadores/as Negros/as (ABPN), [S.1.], v. 7, n. 16, p. 168-189, jun. 2015. ISSN 2177-2770. Disponível em: <http://abpnrevista.org.br/revista/index.php/revistaabpn1/article/view/103>. Acessado em: 14 jun. 2020.

PALHA, Bárbara da Fonseca. Escravidão Negra em Belém: mercado, trabalho e liberdade (18101850). Dissertação (Mestrado em História) - Universidade Federal do Pará, Belém, 2011.

SALLES, Vicente. O negro no Pará: sob o regime de escravidão. $3^{\text {a }}$ edição. Belém: IAP; Programa Raízes, 2005.

SCHWARTZ, Stuart B. Segredos Internos: engenhos e escravos na sociedade colonial (15501835). São Paulo: Companhia das Letras, 1988.

SILVA. Marley Antonia Silva da. A extinção da Companhia de Comércio e o tráfico de africanos para o Estado do Grão-Pará e Rio Negro (1777-1815). Dissertação (Mestrado em História) Universidade Federal do Pará, Belém, 2012.

SOUZA JUNIOR, José Alves de. Tramas do Cotidiano: Religião, Política, Guerra e Negócios no Grão-Pará do setecentos: um estudo sobre a Companhia de Jesus e a política pombalina. Belém: Ed. UFPA, 2012. Originalmente apresentada como Tese de Doutorado, PUC - São Paulo, 2009.

Revista da ABPN • v. 12, n. Ed. Especial - Caderno Temático: "Africanos, escravizados, libertos biografias, imagens e experiências atlânticas" • agosto de 2020 , p. $71-88$ 
VERGOLINO-HENRY, Anaíza \& FIGUEIREDO, Arthur Napoleão. A presença africana na Amazônia colonial: uma notícia histórica. Belém: Arquivo Público do estado do Pará, 1990.

VIANNA, Arthur. As Epidemias no Pará. 2ed. Belém: UFPA, 1975.

Recebido 03/07/2020

Aprovado em 22/07/2020

Revista da ABPN • v. 12, n. Ed. Especial - Caderno Temático: "Africanos, 